\title{
Investigation of Long Term Reactive Stability of Ceria for Use in Solar Thermochemical Cycles
}

\author{
Nathan R. Rhodes, Michael M. Bobek, Kyle M. Allen and David W. Hahn* \\ Department of Mechanical and Aerospace Engineering, University of Florida, P.O. Box 116250, \\ Gainesville, FL 32611-6300, USA; \\ * Author to whom correspondence should be addressed; E-Mail:dwhahn@ufl.edu; \\ Tel: +1-352-392-0807.
}

\begin{abstract}
The use of an intermediate reactive material composed of cerium (IV) oxide (ceria) is explored for solar fuel production through a $\mathrm{CO}_{2}$-splitting thermochemical redox cycle. To this end, powder and porous ceria samples are tested with thermogravimetric analysis (TGA) to ascertain their maximum fuel production potential from the $\mathrm{CeO}_{2} \rightarrow \mathrm{CeO}_{2-\delta}$ cycle. A maximum value of the non-stoichiometric reduction factor $\delta$ of ceria powder was 0.0383 at $1450^{\circ} \mathrm{C}$. The reactive stability of a synthesized porous ceria sample is then observed with carbon dioxide splitting at $1100^{\circ} \mathrm{C}$ and thermal reduction at $1450^{\circ} \mathrm{C}$. Approximately $86.4 \%$ of initial fuel production is retained after 2000 cycles, and the mean value of $\delta$ is found to be 0.0197 . Scanning electron microscopy (SEM) imaging suggests that the porous ceria structure is retained over 2000 cycles despite apparent loss of some surface area. Energy dispersive x-ray spectroscopy (EDS) line scans show that oxidation of porous ceria becomes increasingly homogenous throughout the bulk material over an increasing number of cycles. Significant retention of reactivity and porous structure demonstrates the potential of porous ceria for use in a commercial thermochemical reactor.
\end{abstract}

Keywords: Thermochemical cycle; Ceria; $\mathrm{CO}_{2}$ Splitting; Solar Fuels; Reactive Stability

\section{Introduction}

Given the finite nature of fossil fuel reserves, at present the most widely used source of energy, it is of interest to develop alternative avenues by which energy may be provided in the 
future. Of particular interest is solar energy, which is renewable and widely available. Given its intermittence, the issue of solar energy storage, however, is a critical challenge that must be addressed if the solar resource is to be extensively utilized. One possible pathway is the storage of solar-derived energy in the form of chemical fuels produced by regenerative thermochemical cycles. Many types of thermochemical cycles have been proposed, including both primarily stoichiometric (e.g. iron oxides) and non-stoichiometric (e.g. cerium oxide) mechanisms. While some involve many processes, those of interest here proceed with two steps. The exothermic oxidation of a reactive metal to produce fuel is the first step. The second uses endothermic thermal reduction that removes oxygen from the reactive material, renewing it to the original state for another cycle of fuel production [1]. With water as an oxidizing agent, the resultant chemical fuel is high-purity hydrogen [2] [3] [4]. When a mixture of water and carbon dioxide oxidizes the material, the result is syngas, a combination of hydrogen and carbon monoxide [5] [6] [7] [8]. Xiao et al. summarized recent advances in thermochemical cycling, reviewing a large range of reactive materials for the production of hydrogen and syngas [9]. These products can be directly utilized, or syngas can be further processed to obtain other hydrocarbon-based fuels (e.g. Fisher-Tropsch process).

The intermediate reactive material at the core of the thermochemical redox cycles discussed previously is of considerable significance. Ideally, this material will evolve a large quantity of fuel during the oxidation step and during reduction quickly release all of the oxygen previously incorporated, thereby retaining reactivity for subsequent cycles. Among the first and most popular stoichiometric materials considered were iron oxides such as magnetite $\left(\mathrm{Fe}_{3} \mathrm{O}_{4}\right)$ and hematite $\left(\mathrm{Fe}_{2} \mathrm{O}_{3}\right)$ [10] [11] [12] [13]. While these iron oxides have exhibited promising oxidative potential, they are often supplemented with the addition of other metals (Co, Mn, $\mathrm{Ni}$, etc.) and/or zirconia substrates to avoid the deactivating effects of sintering at high reduction temperatures [14] [15] [16] [17]. For example, Song et al. demonstrated a synthesis of iron with mesoporous Si-doped alumina that exhibited a significant reduction in deactivation for hydrogen productivity over three cycles [18]. Zinc oxide is another popular choice for stoichiometric thermochemical cycling. During the reduction step, however, zinc oxide 
experiences a significant vaporization effect that necessitates quenching or other steps to recuperate the original reactive state [19] [20].

Recently, cerium(IV) oxide, i.e. ceria, has been examined as a candidate for thermochemical cycling. Equation 1 shows the non-stoichiometric release of oxygen during thermal reduction of ceria at high temperature. Equations 2 and 3 demonstrate the evolution of hydrogen or $\mathrm{CO}$ from the oxidizing agents of water or carbon dioxide, respectively [21].

$$
\begin{gathered}
\mathrm{CeO}_{2} \rightarrow \mathrm{CeO}_{2-\delta}+\frac{\delta}{2} \mathrm{O}_{2} \\
\delta \mathrm{H}_{2} \mathrm{O}+\mathrm{CeO}_{2-\delta} \rightarrow \mathrm{CeO}_{2}+\delta \mathrm{H}_{2} \\
\delta \mathrm{CO}_{2}+\mathrm{CeO}_{2-\delta} \rightarrow \mathrm{CeO}_{2}+\delta \mathrm{CO}
\end{gathered}
$$

When performed below ceria's melting point of approximately $2000^{\circ} \mathrm{C}$, the reduction proceeds globally in a non-stoichiometric fashion. The figure of $\delta$ in the above steps represents the degree of non-stoichiometry present in the process, which also describes its fuel production potential. More specifically, the dimensionless $\delta$ can be defined as the number of moles of vacancies per mole of cerium. These vacancies are created by the mobility of oxygen in the ceria lattice during the reduction step, noted in Equation 1. The particular value of $\delta$ depends highly on material structure and reactive conditions. Bulfin et al. recently developed a model for the thermal reduction of ceria that predicts temperature and local oxygen partial pressure to significantly impact $\delta$. In particular, an environment of increased oxygen partial pressure is shown to have a substantially damaging effect on $\delta$. A theoretical maximum value of $\delta=0.32$ was determined for conditions of $2000^{\circ} \mathrm{C}$ and an oxygen partial pressure of $10^{-7}$ bar. Potential commercial cycles employing ceria would likely operate with much lower values of $\delta$, for the previously mentioned conditions approach the melting point of ceria and requires exceptionally low pressure. Bulfin's model predicts a $\delta$ of approximately 0.04 for perhaps more practical conditions of $1600^{\circ} \mathrm{C}$ and $10^{-3}$ bar [21].

Many forms and structures of ceria, such as powders [22], doped and ceramic-supported structures [23] [24] [25] [26], monolithic foams [27] [28] [29], and felts [5] have been examined 
for thermochemical cycling applications. Solar simulating reactors have also incorporated monolithic ceria structures to demonstrate their feasibility for practical implementation [5] [27] [28] [29]. While ceria has been noted for its oxygen storage capacity and its redox potential, onsun reactors often suffer from very low solar-to fuel efficiencies on the order of approximately 1-2\%. As reactor design improves, efficiency increases are possible. For instance, Lapp et al. modeled a dramatic increase of reactor efficiency from $3.5 \%$ to $16 \%$ with moderate heat recovery [30]. Furthermore, for successful utilization in a solar thermochemical reactor, the physical structure of ceria needs to be optimized for maximum fuel production and reduction potential. While initial production rates over the first few cycles are important to the preliminary selection of promising reactive material candidates, stability of long term production over thousands or tens of thousands of cycles is arguably of equal significance for the purposes of successful commercialization. To this end, Chueh and Haile performed 500 thermochemical cycles of porous ceria. Hydrogen production decreased by $25 \%$ after 100 cycles, and production held relatively stable thereafter [31]. To date, however, literature is largely lacking in the study of ceria over an extended number of cycles. This study will focus on the reactive potential of several ceria structures as well as an extended test of the most promising candidate over 2000 cycles. Reactivity data over many cycles will further characterize the potential for the utilization of ceria in a commercially viable solar thermochemical reactor.

\section{Experimental Methods}

\subsection{Data Acquisition}

All experiments were conducted with thermogravimetric analysis (TGA) (Netzsch STA 449 Jupiter) and analyzed with a combination of Netzsch Proteus Thermal Analysis and Microsoft Excel. A control experiment is required for each unique set of experimental conditions. This corrective run accounts for the effects of thermal buoyancy and gas flow changes on the mass change recorded by the balance. After each experiment is run, per manufacturer recommendation, the mass change from the associated corrective run is subtracted from the results. This subtraction ensures that the data reflects mass change due to only a specimen's reaction in the experimental conditions. 
For morphological inspection, specimens were set in epoxy (ExpoxiCure 20-8130-032) to prepare them for polishing. Thereafter, they were imaged with scanning electron microscopy (SEM) and energy dispersive x-ray spectroscopy (EDS). Images were obtained with a Jeol SEM-

6400. SEM images provide insight into the morphological structure of specimens and how their structures may change over time. EDS line scans characterize elemental composition of specimens so that potential gradients of reactivity within individual particles may be identified. Unreacted ceria powder and SPF-G ceria were used as standards to quantify the EDS O/Ce atomic data along with a two-point linear calibration curve.

\subsection{Sample Preparation}

Three forms of ceria were used in this study: micron-sized powder, nano-sized powder, and a synthesized porous structure. The micron-sized powder (Alpha Aesar 12925 contains particle sizes ranging from 5.2 to 8 microns in diameter. Nano-sized powder (Sigma Aldrich 544841) is comprised of particles with diameters less than $25 \mathrm{~nm}$. The porous ceria sample was prepared using a sacrificial pore formation using graphite (SPF-G) method. This method entails mixing graphite particles into ceria powder and oxidizing the mixture in air at high temperature. During this process, the graphite reacts to form carbon monoxide and is emitted from the structure. After ceria particles sinter, the result is a solid, porous ceria structure that is free of graphite. More details on this procedure can be found in the recent work by Allen et al. [32]. For this study, equal parts (by mass) of micron-sized ceria, mesh 325 graphite, and mesh 40 graphite powders were combined and heat treated in an alumina tube furnace.

\subsection{Experimental Procedure}

During experimentation, samples were housed in alumina crucibles. Ultra high purity (UHP) argon was used as inert flow and was passed through an Agilent adsorbent bed to remove any residual traces of oxygen and other impurities prior to introduction to the TG. UHP carbon dioxide was used as received as the oxidizing agent. Before experimentation, the TG was evacuated and backfilled with argon to remove oxygen and water vapor from the reactive chamber. The balance was allowed to equilibrate at ambient temperature and pressure for at least one hour prior to the initiation of each experiment. 
Two primary sets of experiments were conducted, both using oxidation under $120 \mathrm{~cm}^{3}$ of carbon dioxide and thermal reduction under $120 \mathrm{~cm}^{3}$ of argon. Additionally, a $20 \mathrm{~cm}^{3}$ argon flow was present at all times as a protective gas stream. Oxidation was conducted down to $1100^{\circ} \mathrm{C}$ while reduction occurred up to $1450^{\circ} \mathrm{C}$. This $\Delta \mathrm{T}$ of $350^{\circ} \mathrm{C}$ is near the point at which Ermanoski and others predicted that a thermochemical cycle may achieve a maximum efficiency [33]. A universal heating and cooling rate of $50^{\circ} \mathrm{C} / \mathrm{min}$ was used for all temperature ramps. What we consider as equilibrium experiments consist of a single cycle of reduction and oxidation, holding each for 8 hours to capture the full extent of reaction for a given sample. Four experiments with varying sample masses of both micro and nano ceria powders were run to test a possible effect of absolute mass on maximum reduction and oxidation extent.

The 2000 cycle experimental set is divided into individual experiments of 50 cycles each due to TG temperature program constraints. Each set of 50 cycles was performed successively with the sample protected by an inert argon stream between runs. Samples were cycled between $1100^{\circ} \mathrm{C}$ and $1450^{\circ} \mathrm{C}$ without dwell time at either temperature. Oxidation with carbon dioxide began at $1300^{\circ} \mathrm{C}$ on the ramp down to $1100^{\circ} \mathrm{C}$. The oxidizing flow is stopped upon reaching $1100^{\circ} \mathrm{C}$, at which point a new cycle begins and temperature ramps up again under inert flow. Two ceria SPF-G samples were tested with this procedure: one was carried to 500 cycles while the second completed 2000 cycles. After completion of the experimental set, samples were allowed to cool to room temperature under argon before being removed for morphological analysis.

\section{Results and Discussion}

\subsection{Reduction and Oxidation to Equilibrium}

Figure 1 depicts a representative image of the extent of reduction and oxidation of 99.53 $\mathrm{mg}$ of the micron-sized ceria. While the majority of mass loss occurred during the first two hours of thermal reduction, loss continues for the extent of the 8 hour step. Oxidation under carbon dioxide appears to complete much more quickly, reaching a maximum value almost immediately after the onset of oxidation. The difference between the minimum mass during reduction and the maximum during oxidation measures approximately $0.353 \mathrm{mg}$, which 
corresponds to a non-stoichiometric reduction $\delta$ value of 0.0382 for the sample mass of 99.53 mg (e.g. $\mathrm{CeO}_{2} \rightarrow \mathrm{CeO}_{2-\delta}$ ).

For each particle size, four experiments with different sample masses were run in conditions identical to that used in Figure 1. Table 1 shows a summary of the results. Micronsized powder samples with masses of approximately 100, 75, 50, and $25 \mathrm{mg}$ were tested, and the average value of $\delta$ is $0.0383 \pm 0.0004$. Each experiment exhibited very similar behavior on a per mass basis, resulting in a very low standard deviation. Nano-sized powder samples demonstrated similar behavior: samples with masses of approximately 35, 30, 20, and $10 \mathrm{mg}$ exhibited an average $\delta$ of $0.0373 \pm 0.0028$. While slightly higher than that of micron-sized powder, the deviation between the $\delta$ of different masses is again low, roughly $7.5 \%$ of the average value. Low deviation suggests that the redox capacity of ceria powder is not dependent upon the absolute mass of ceria when taken to equilibrium. Despite theoretically possessing a lesser amount of surface area per mass, micron-sized ceria powder outperformed nano-sized powder by $2.6 \%$ in terms of $\delta$. This difference in performance between powders is small, however, and is likely not indicative of a statistically significant advantage of this micron-sized ceria powder over nano-sized powder $(t=0.6137, p<0.05)$. Importantly, such a result suggests that diffusion and vacancy mobility is not considered limiting over these size dimensions between $25 \mathrm{~nm}$ to $8 \mu \mathrm{m}$ at these time scales. 


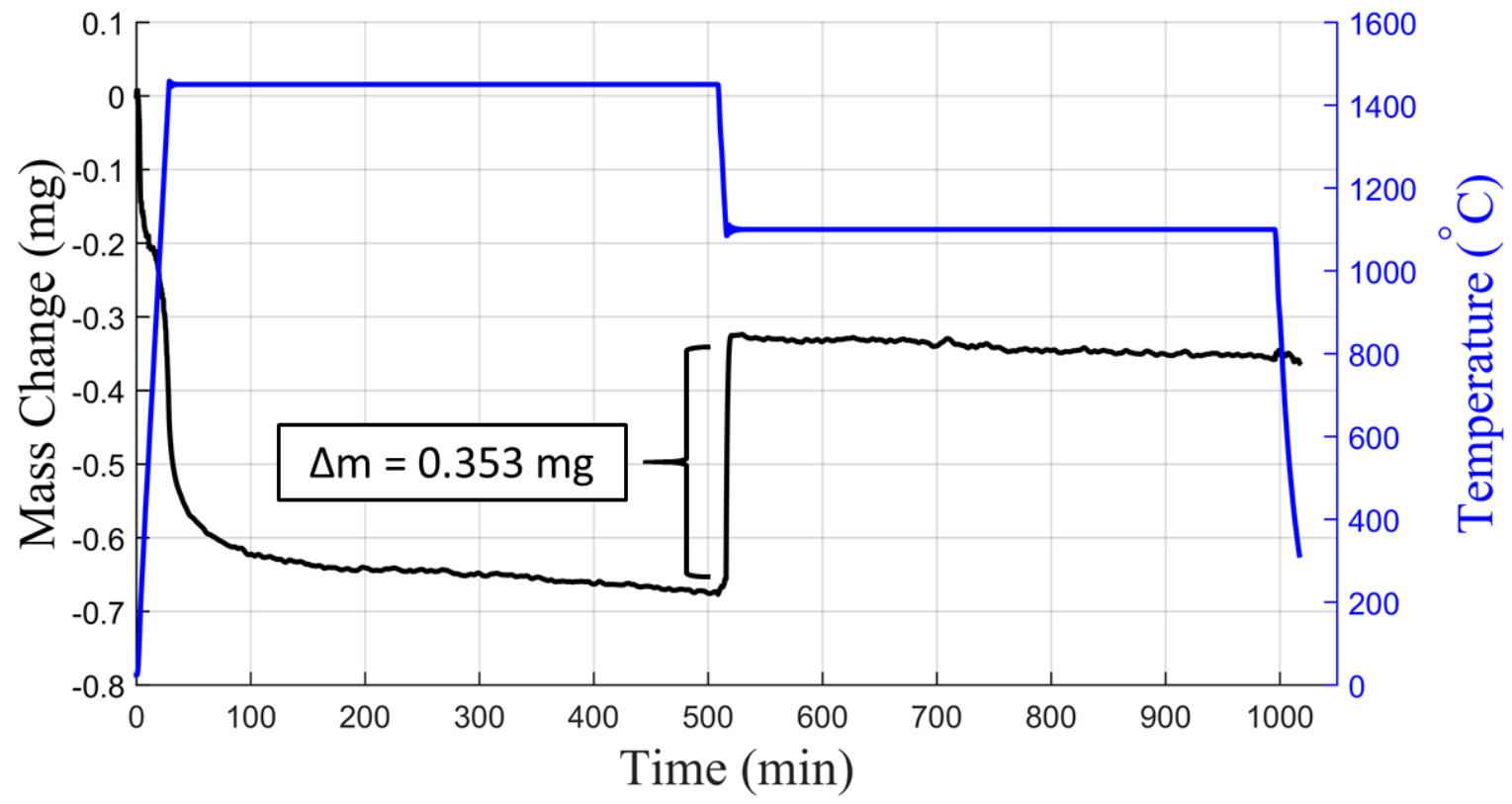

Figure 1. Reduction and oxidation of $99.53 \mathrm{mg}$ of micron-sized ceria powder to near-equilibrium states. Reduction is conducted at $1450^{\circ} \mathrm{C}$ under inert flow while oxidation occurs at $1100^{\circ} \mathrm{C}$ under carbon dioxide. Both steps are held for 8 hours.

Table 1. Summary of results from reduction and oxidation to near-equilibrium states for micron and nano-sized ceria powders.

\begin{tabular}{|c|c|c|c|c|c|}
\hline & $\begin{array}{c}\text { Initial } \\
\text { Mass (mg) }\end{array}$ & $\Delta \mathrm{m}(\mathrm{mg})$ & $\delta$ & Average $\delta$ & St. Dev. \\
\hline \multirow{4}{*}{$\begin{array}{c}\text { Micron-Sized } \\
\text { Powder }\end{array}$} & 99.53 & 0.354 & 0.0382 & \multirow{4}{*}{0.0383} & \multirow{4}{*}{0.0004} \\
\hline & 74.72 & 0.263 & 0.0378 & & \\
\hline & 50.28 & 0.181 & 0.0388 & & \\
\hline & 25.30 & 0.090 & 0.0382 & & \\
\hline \multirow{4}{*}{$\begin{array}{l}\text { Nano-Sized } \\
\text { Powder }\end{array}$} & 35.43 & 0.121 & 0.0367 & \multirow{4}{*}{0.0373} & \multirow{4}{*}{0.0028} \\
\hline & 29.93 & 0.100 & 0.0358 & & \\
\hline & 19.60 & 0.064 & 0.0354 & & \\
\hline & 9.90 & 0.038 & 0.0415 & & \\
\hline
\end{tabular}

SEM imaging of micron-sized ceria powder is depicted in Figure 2. A difference in particle size is apparent between fresh, uncycled ceria powder and identical powder that has been exposed to oxidizing conditions under $\mathrm{CO}_{2}$ at $1100^{\circ} \mathrm{C}$ for 8 hours. After oxidation, particle size appears much larger than that in uncycled powder. This observation lends credence to the 
theory of powdered ceria particles sintering after being exposed to high temperature. The sintering phenomenon and associated loss of surface area may not only contribute to the loss of reactivity seen after approximately 3 hours of oxidation in Figure 1, but also to decreasing reactivity over multiple redox cycles.

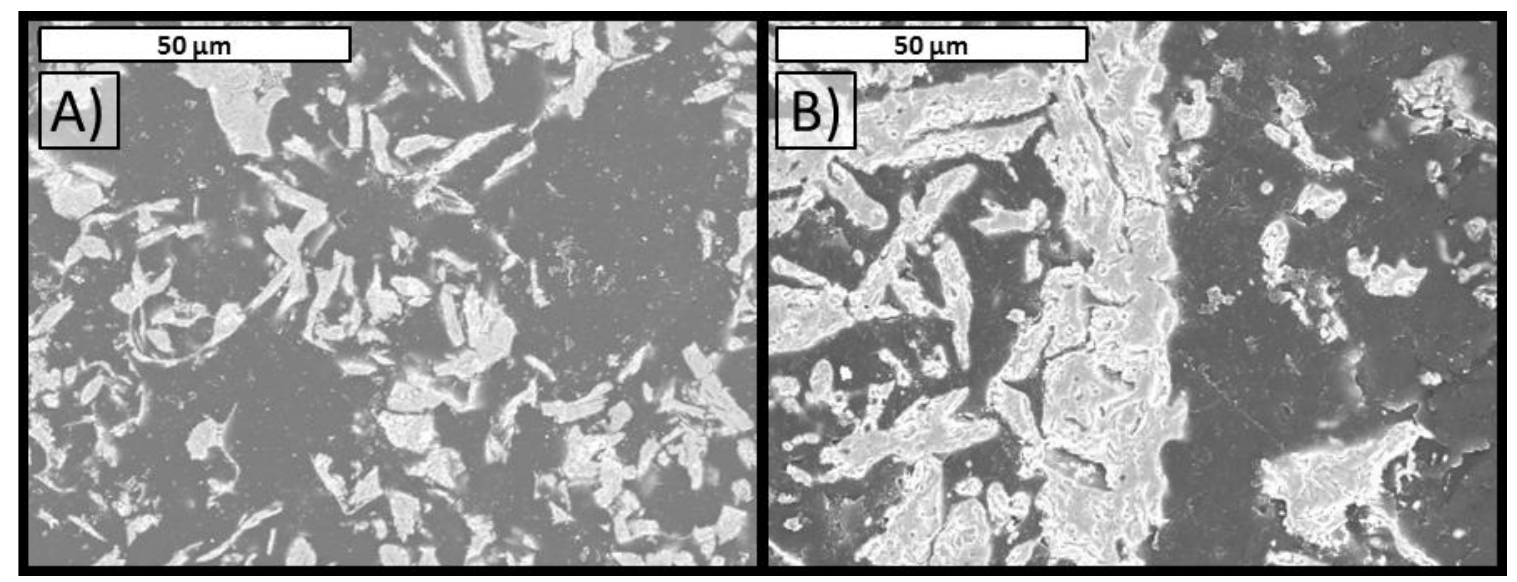

Figure 2. SEM images (1000x) of micron-sized ceria powder $\mathrm{A}$ ) before oxidation and B) after 8 hours of oxidation under $\mathrm{CO}_{2}$ at $1100^{\circ} \mathrm{C}$.

EDS line scans of micron-sized ceria powder show consistent oxygen:cerium signal ratios across the length of a particle. There is no apparent gradient trend of O:Ce from the surface of a ceria particle to its center. Such an observation implies that oxidation and reduction of these powder samples to a state of quasi-equilibrium allows for uniform reactivity throughout a ceria particle, suggesting oxygen vacancy mobility. Average signal ratios across two samples are compared in Table 2. The first sample is only oxidized for 8 hours and is imaged "following oxidation." The second experienced a single complete cycle of oxidation and reduction for 8 hours each, identical to that show in Figure 1. It is imaged "following reduction." The O:Ce ratio noted after reduction is lower than that after oxidation, but the difference is quite small and is contained within a single standard deviation of the data. Further work involving the cycling and subsequent imaging of ceria powder to a range of oxidative states may be required to better judge the significance of this small difference in O:Ce ratio between powders before and after the reduction step. 
Table 2. Average oxygen:ceria signal ratios from EDS line scans across micron-sized ceria powder particles after oxidation and a single complete cycle of oxidation and reduction.

\begin{tabular}{|c|c|c|}
\hline & $\begin{array}{c}\text { Average O:Ce } \\
\text { Signal Ratio }\end{array}$ & $\begin{array}{c}\text { Standard } \\
\text { Deviation }\end{array}$ \\
\hline $\begin{array}{c}\text { Following } \\
\text { Oxidation }\end{array}$ & 0.64842 & 0.05173 \\
\hline $\begin{array}{l}\text { Following } \\
\text { Reduction }\end{array}$ & 0.63837 & 0.03641 \\
\hline & \multicolumn{2}{|c|}{$\%$ Loss of Oxygen Signal } \\
\cline { 2 - 3 } & \multicolumn{2}{|c|}{$0.01550 \%$} \\
\hline
\end{tabular}

Images of the powder samples after reduction to equilibrium and subsequent oxidation are shown in Figure 3. The sample on the left of the image began as $29.93 \mathrm{mg}$ of nano-sized powder while that on the right began as $74.72 \mathrm{mg}$ of micron-sized powder. Both samples are sintered into a solid mass after experimentation and reduced significantly in terms of volume. As surface area is an important metric in long term solar fuel production, a structure that better resists sintering is of interest. To address this point, a porous ceria structure formed with the SPF-G method was subjected to the same cycle conditions as the pure powder samples. The value of $\delta$ for the SPF-G sample was calculated to be 0.0373 , nearly identical to that of the nano-sized powders. However, physical changes in this sample were much less prominent. Figure 4 shows the SPF-G sample after experimentation, and the structure appears largely unchanged after a single cycle. 


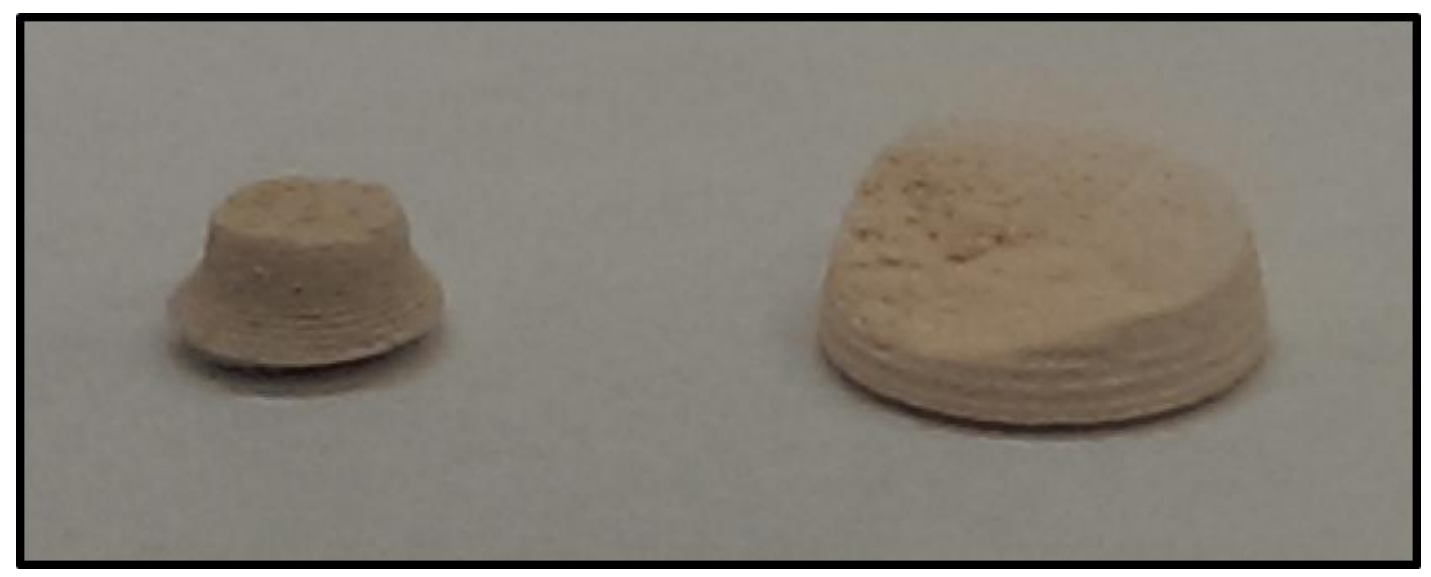

Figure 3. Micron and nano-sized powder samples after 8 hours of reduction at $1450^{\circ} \mathrm{C}$ and 8 hours of oxidation under carbon dioxide at $1100^{\circ} \mathrm{C}$. The sample on the left began as nano-sized powder, and that on the right began as micron-sized powder.

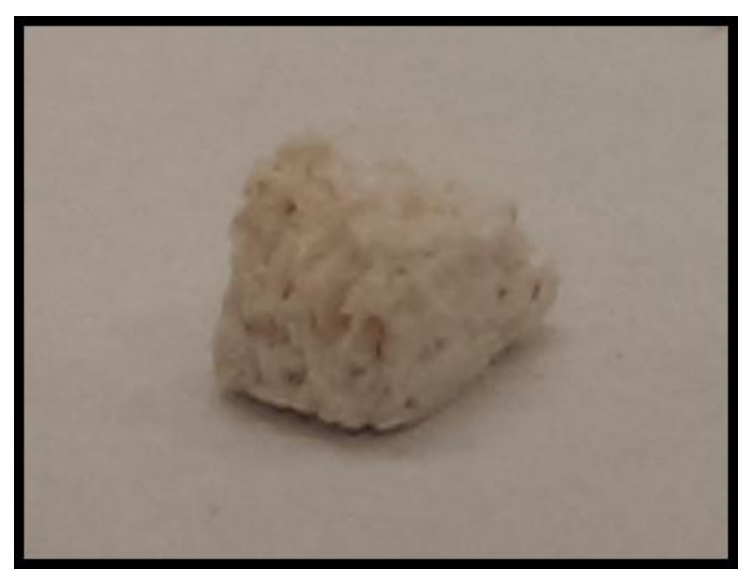

Figure 4. Ceria structure formed by the SPF-G method after 8 hours of reduction at $1450^{\circ} \mathrm{C}$ and 8 hours of oxidation under carbon dioxide at $1100^{\circ} \mathrm{C}$.

Given the comparable performance with regard to $\delta$ combined with the structural integrity and stability of ceria SPF-G over a single cycle, this material is chosen for the 2000 cycle experiment to investigate its long term reactive stability. However, an intermediate experiment to determine optimal cycle dwell times was conducted. An optimized cycle should incorporate dwell times during oxidation and reduction that maximize fuel production on the basis of time over many cycles, recognizing that full 16 hour cycles are not practical. Results from Figure 1 suggest that oxidation occurs very quickly and that dwell time during that step 
should be minimized. Figure 5 shows the results from the intermediate test, in which a 100.27 mg ceria SPF-G specimen is reduced for 8 hours at $1450^{\circ} \mathrm{C}$, oxidized with carbon dioxide during the ramp down to $1100^{\circ} \mathrm{C}$, and immediately ramped back to $1450^{\circ} \mathrm{C}$ for 8 additional hours of reduction with no dwell time during oxidation. A view of oxygen production rate during the ramp up in temperature and immediately after completion of the oxidation step is shown in Figure $5 \mathrm{~b}$. The production rate reaches a maximum as the temperature ramp comes to an end after 7 minutes. Such behavior suggests that, for these temperature and gas flow conditions, it is optimal to include zero dwell time after the ramp up to $1450^{\circ} \mathrm{C}$.
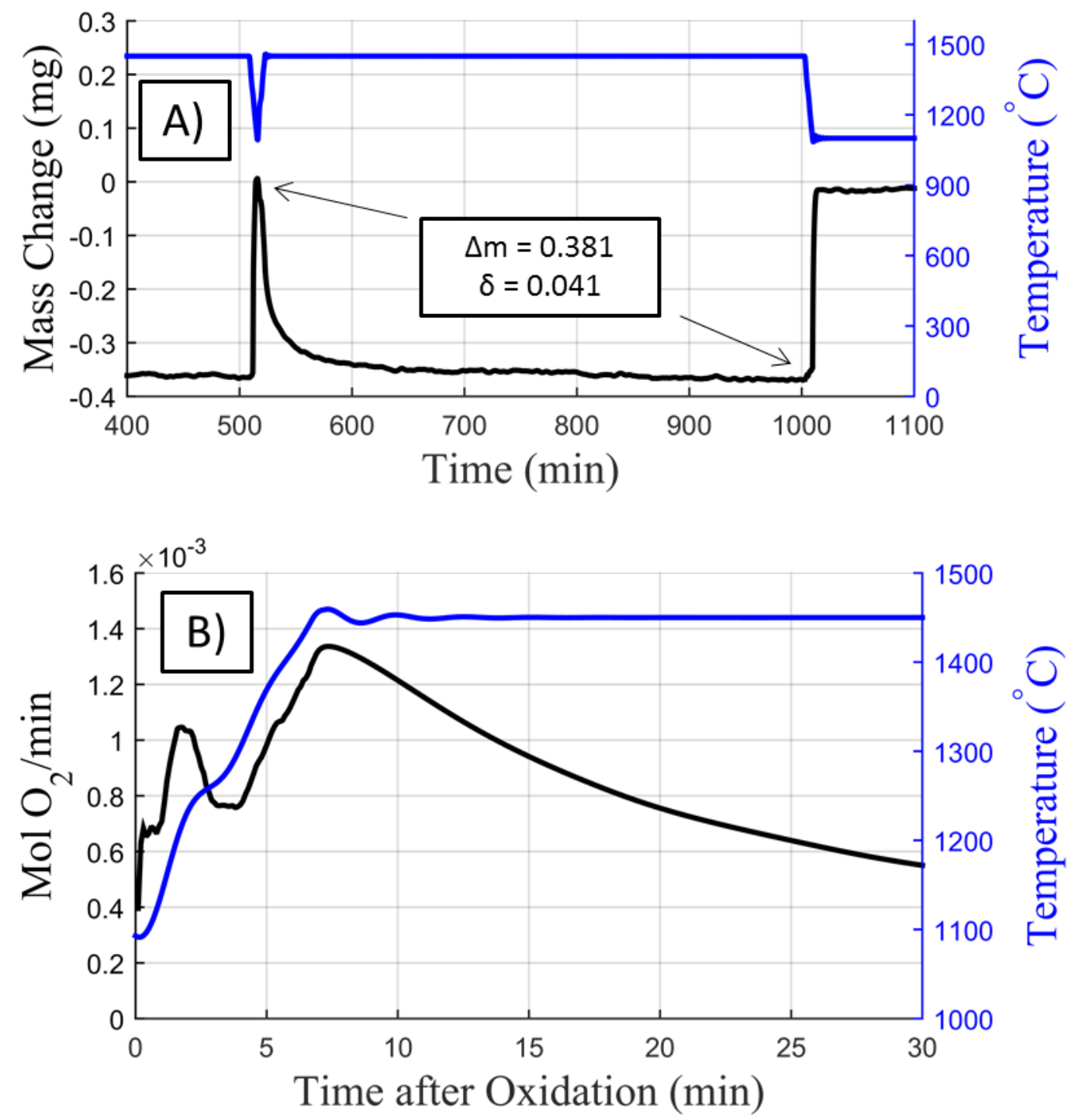
Figure 5. A) Ceria SPF-G structure oxidized with no dwell time at $1100^{\circ} \mathrm{C}$ with carbon dioxide between two 8 hour thermal reduction steps at $1450^{\circ} \mathrm{C}$. B) Production rate of oxygen after completion of the oxidation step.

\subsection{Stability over 2000 Cycles}

\subsubsection{TGA Investigation}

To promote maximum production during the 2000 cycle test, a "sawtooth" temperature profile with no dwell time is employed. Figure 6 shows representative TG data of 20 such cycles with a ceria SPF-G sample. As was previously determined, thermal reduction occurs during the ramp up between $1100^{\circ} \mathrm{C}$ and $1450^{\circ} \mathrm{C}$ while oxidation with carbon dioxide occurs during the ramp down between $1300^{\circ} \mathrm{C}$ and $1100^{\circ} \mathrm{C}$ without dwell time at any temperature. With 7 minutes for each ramp in temperature, the total time required for a single cycle is 14 minutes.

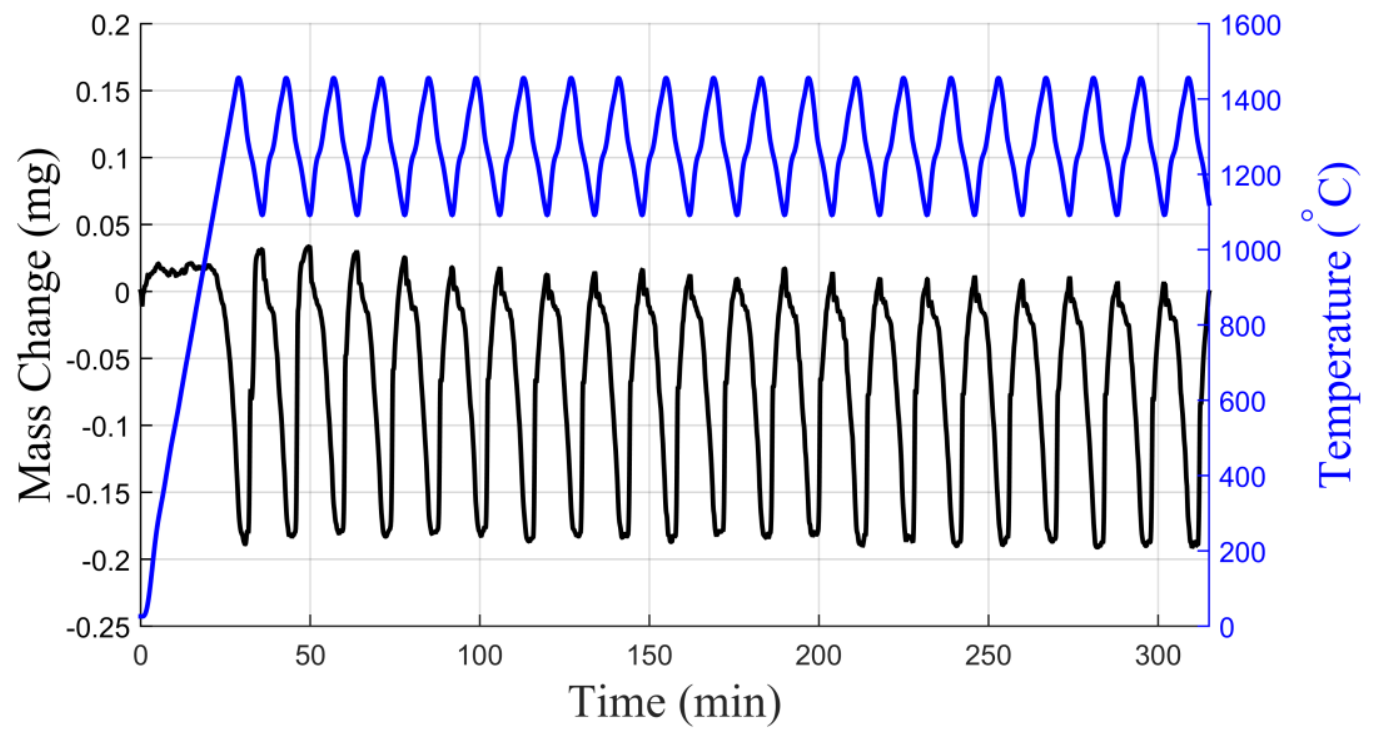

Figure 6. TG data of 20 redox cycles of ceria SPF-G between $1450^{\circ} \mathrm{C}$ and $1100^{\circ} \mathrm{C}$. Thermal reduction occurs during the ramp up from $1100^{\circ} \mathrm{C}$ to $1450^{\circ} \mathrm{C}$ while oxidation with carbon dioxide in conducted during the ramp down between temperatures. Total cycle time is 14 minutes.

Although the SPF-G structure has been selected for the 2000 cycle study, it is still of interest to compare the performance of the micron and nano-sized ceria powders on a scale greater 
than a single cycle, as well as for shortened dwell time. A plot of $\delta$ is shown in Figure 7 for 50 cycle tests of micron-sized powder, nano-sized powder, and ceria SPF-G. Due to shorter reduction times, values of $\delta$ are about 40 to $50 \%$ smaller than those seen in Table 1 , which is expected. Due to occurrence of peak reduction rate at the completion of the temperature ramp, however, this scheme increases absolute production on the basis of time. Over 50 cycles, nano-sized ceria powder exhibited the greatest performance while micron-sized ceria demonstrated smaller $\delta$ values than either nano-sized powder or the SPF-G sample. Of further note is that nano-sized powder shows a greater variance in $\delta$ over the cycles in comparison to the micron-sized powder and ceria SPF-G samples, which is consistent with data in Table 1. Note also that the greater sintering of the nanopowder is expected to reduce mass transport of reactants (e.g. steam) within larger scale porous bed structures. Given the stability and repeatability of the performance of ceria SPF-G over nano-sized ceria powder, greater production than that of micron-sized powder, and better expected mass transport, the SPF-G structure is reaffirmed as the sample of interest for the 2000 cycle stability experiment. 


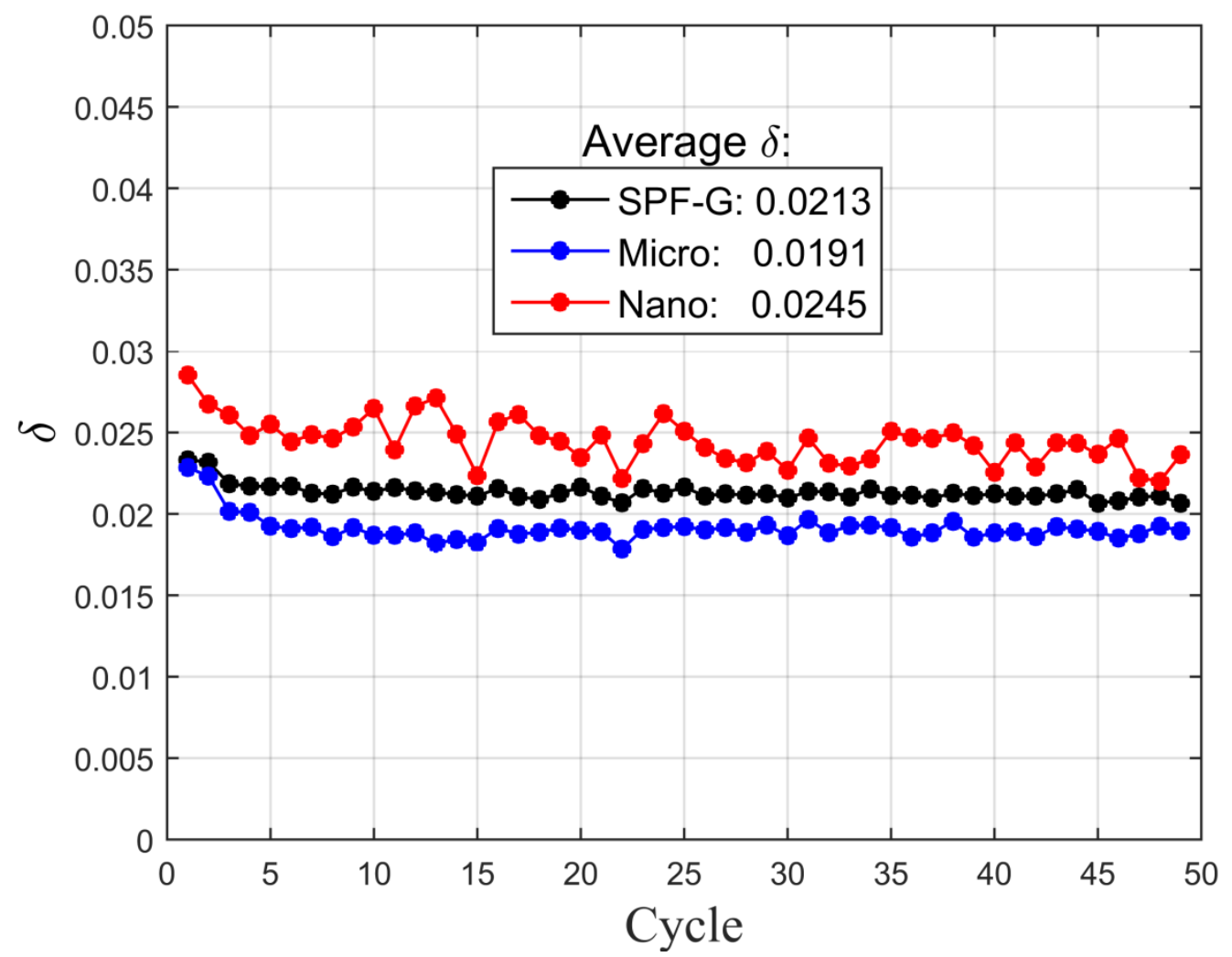

Figure 7. Comparison of $\delta$ over 50 cycles between $1450^{\circ} \mathrm{C}$ and $1100^{\circ} \mathrm{C}$ without dwell time of ceria SPF-G, micron-sized powder, and nano-sized powder.

The average value of $\delta$ for each set of 50 cycles in the 2000 cycle ceria SPF-G stability experiment is shown in Figure 8. A single set of cycles is represented by the presented data. After an initial decrease after the first 50 cycles, $\delta$ values exhibit a relatively constant although slightly downward trend. It is only after approximately 1500 cycles that performance shows the greatest drop between any two sets of cycles. During the final 500 cycles, a downward trend is not as apparent. Production exhibits a slight upward trend in the last 150 cycles. The greatest value of $\delta, 0.0214$, was attained during the first set of cycles. The last set of cycles shows a $\delta$ of 0.0185 , which corresponds to a retention of $86.4 \%$ of reduction potential from the initial 50 cycles. Additionally, the average $\delta$ constitutes approximately $48 \%$ of the value of 0.041 
exhibited by ceria SPF-G in the near-equilibrium cycle shown in Figure 5a. The difference in average $\delta$ between the equilibrium experiments and the 2000 cycle test can be attributed in part to the shorter reduction times in each cycle of the 2000 cycle test, and perhaps also to kinetics alone or vacancy diffusion. During each cycle, the time allotted for reduction is not enough to fully reduce the ceria to the point seen in the near-equilibrium experiments. Additionally, and even with the porous ceria structure, some degree of sintering and subsequent loss of reactivity is present.

With a 500 cycle test of porous ceria, Chueh and Haile realized $75 \%$ of initial hydrogen productivity after 100 cycles and noted stable production thereafter. Our observation of slight but continuous decline of productivity over 2000 cycles may be due to exposure to higher temperature $\left(1000^{\circ} \mathrm{C}\right.$ here vs. Chueh and Haile's $\left.800^{\circ} \mathrm{C}\right)$ and subsequent potential sintering. The number of cycles for the full effect of sintering to be realized may be extended in our study given our zero dwell times at oxidation and reduction target temperature compared to 20 minute total dwell time for Chueh and Haile. While true reactive stability was not realized after our 2000 cycles, the observation of stability by Chueh and Haile lends evidence that achieving 
stability with ceria is possible [31].

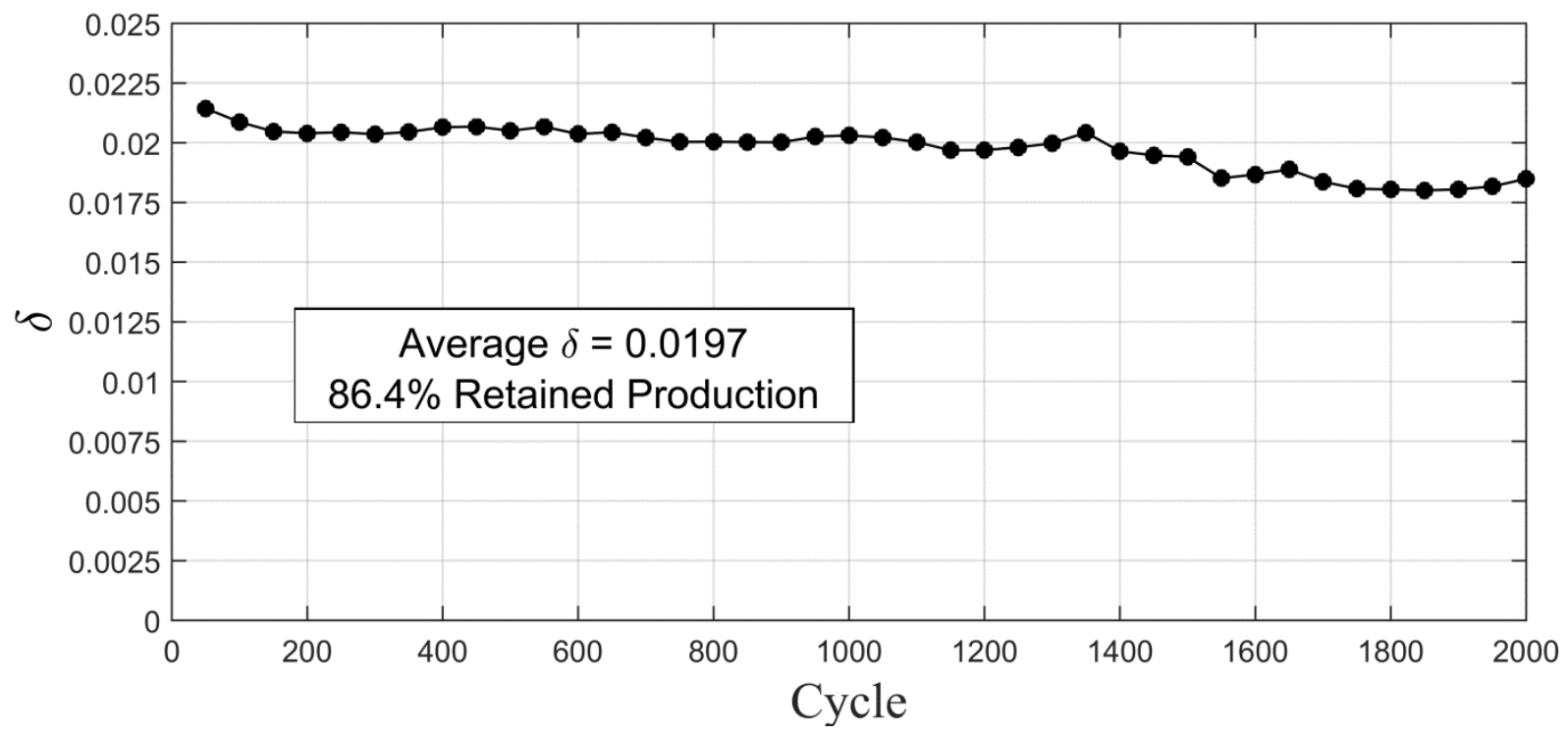

Figure 8. Average value of $\delta$ for each set of 50 cycles over the single 2000 cycle experiment with ceria SPF-G.

\subsubsection{SEM and EDS Imaging}

Upon completion of 2000 cycles, the ceria SPF-G sample was removed from the TG and quickly prepared for imaging with SEM and EDS. For comparison and visualization of the progression of morphological behavior, both uncycled ceria SPF-G and a single specimen cycled to only 500 cycles were also imaged. SEM images of these three samples are shown in Figure 9. Numerous small pores, indicative of the porous SPF-G structure, are present in each of the images. Though the images appear similar overall, fewer small pores are apparent in the cycled samples. The difference in pore size appears greater between the uncycled and 500 cycle samples when compared to that between the 500 and 2000 cycle specimens. Pore size reduction with increasing numbers of cycles implies that sintering may still play a role even while the general porous structure is retained over many cycles. Reduction of surface area due to shrinking pores may be related to the decrease of reactivity noted in Figure 8. Given the similarity of pore sizes between the 500 and 2000 cycle sample images, however, the effect of sintering may be limited once a large number of cycles has been completed. 


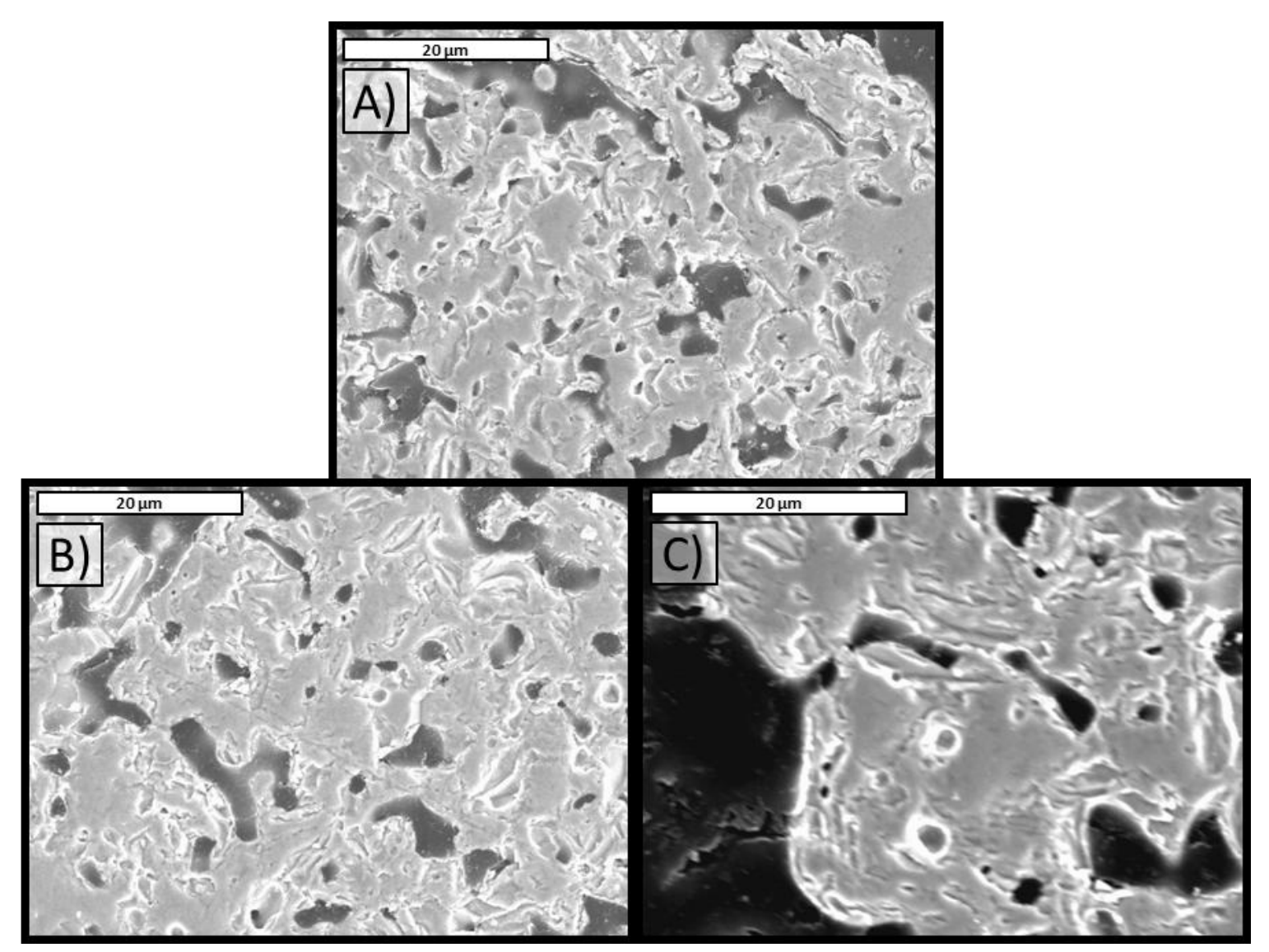

Figure 9. SEM images of ceria SPF-G specimens: A) uncycled sample at 2000x, B) 500 cycle sample at 2000x, and C) 2000 cycle sample at 2500x.

Figure 10 displays moving average plots of EDS line scan data of the three samples shown in Figure 9. Oxygen:cerium ratios are shown across a normalized distance which begins at the surface of a sample and proceeds into the bulk. Cycled samples were removed from the TG after an oxidation step, so oxygen levels should be pronounced. Table 3 shows the average O:Ce ratios, resting between 0.5 and 0.6 , to be similar for each case. Notable is the decreasing standard deviation of signal ratios across a sample with an increasing number of cycles. The uncycled ceria SPF-G displays a standard deviation of approximately 0.3 , thrice as high as that of the sample subjected to 2000 cycles. This suggest a homogenization of the material as additional cycles are performed. The sharp dip in the signal ratio of the 500 cycle sample roughly between the distance of 0.5 and 0.7 is due to the presence of a small pore. Other than this dip, the ratios remain relatively constant across the cycled samples. The lack of a clear trend between oxygen and ceria ratios in cycled ceria samples suggests that the oxidation of porous 
ceria may be considered homogenous without a significant gradient of oxidation from the surface of the material into the bulk and provides evidence that oxygen mobility/diffusion is not a limiting issue.

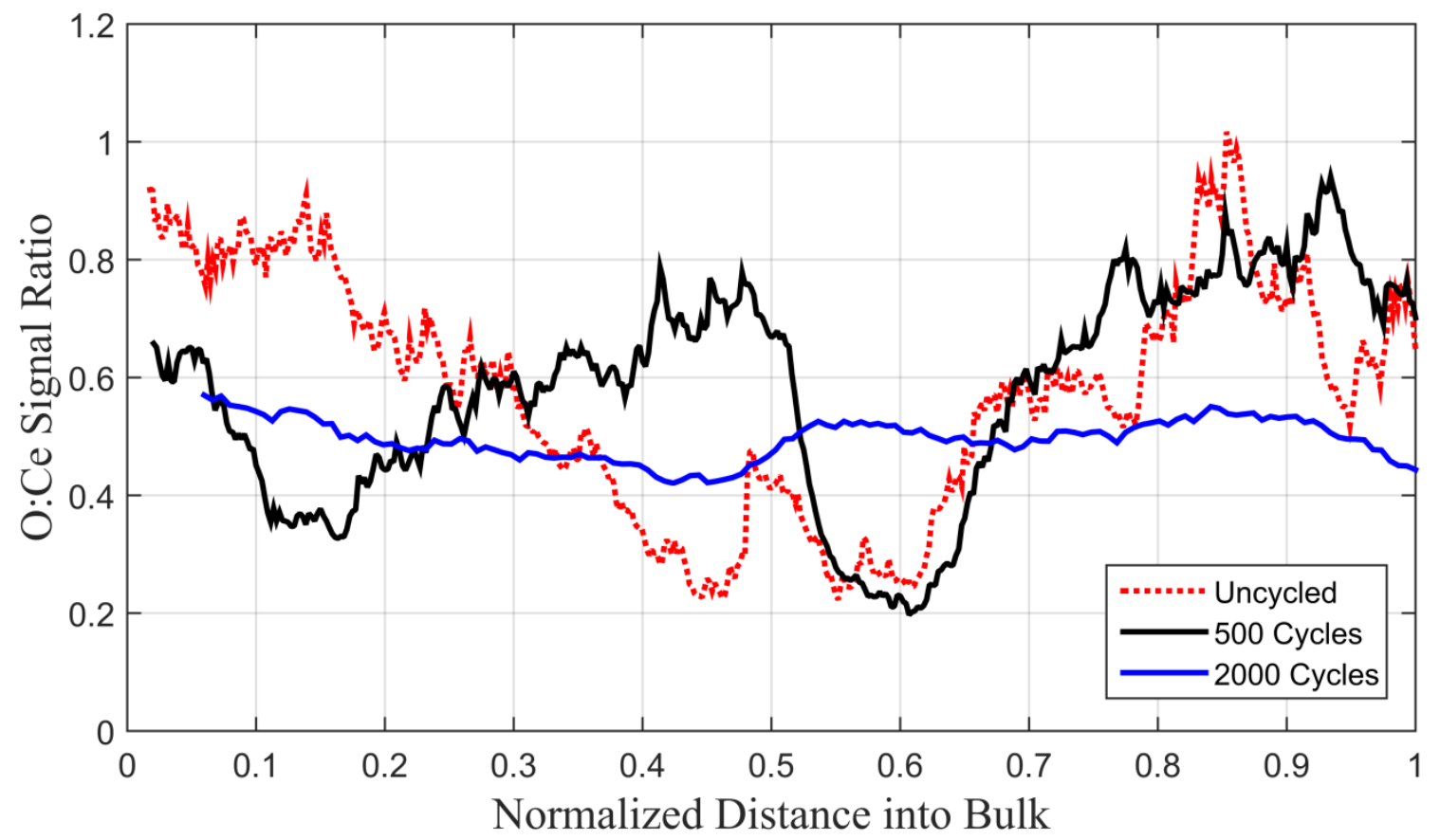

Figure 10. Moving average plots of EDS line scans of oxygen to cerium signal ratios across ceria SPF-G samples that have undergone zero, 500, and 2000 cycles. Distance into a particle is normalized and begins at the surface of a particle (0) to particle center (1).

Table 3. Average oxygen to ceria signal ratios for ceria SPF-G samples subjected to zero, 500, and 2000 cycles.

\begin{tabular}{|c|c|c|}
\hline & $\begin{array}{c}\text { Average O:Ce } \\
\text { Signal Ratio }\end{array}$ & $\begin{array}{c}\text { Standard } \\
\text { Deviation }\end{array}$ \\
\hline Uncycled Ceria SPF-G & 0.581 & 0.309 \\
\hline After 500 Cycles & 0.585 & 0.259 \\
\hline After 2000 Cycles & 0.535 & 0.106 \\
\hline
\end{tabular}

\section{Conclusion}

The intermediate reactive material is key to the success of a solar thermochemical reactor. For such a reactor to be commercially viable, its reactive material must be able to perform consistently over thousands or perhaps hundreds of thousands of cycles. While initial fuel 
production rates over several cycles are important in determining material candidates, long term production capability is equally important for the successful implementation of solar thermochemical cycling technology. Using TGA, ceria micron and nano-sized powder samples were thermally reduced at $1450^{\circ} \mathrm{C}$ and oxidized with carbon dioxide at $1100^{\circ} \mathrm{C}$, each with a dwell time of 8 hours so that states of near-equilibrium could be attained. We estimate the oxygen partial pressure during experimentation to be approximately $10^{-5}$ bar. The maximum capacity of reactivity, noted by the non-stoichiometric factor $\delta$, for these conditions was determined to be 0.0383 . This result demonstrates good agreement with Bulfin's analytical model, which predicts a $\delta$ of approximately 0.04 for the thermal reduction of ceria at $1450^{\circ} \mathrm{C}$ with an oxygen partial pressure of $10^{-5}$ bar [21].

Due to the significant degree of sintering identified with powder samples during equilibrium cycles, a porous structure of ceria was created using the SPF-G method. This sample exhibited a similar maximum $\delta$ and more readily resisted sintering effects. The ceria SPF-G sample was selected for a 2000 cycle study to test its potential for long term fuel production, and the value seen in the last 50 cycles is $86.4 \%$ of that seen in the first set of 50 cycles. The difference in $\delta$ noted between the equilibrium cycles and the average of the 2000 cycle set is attributed to both a shorter reduction dwell time and reactive degradation over an extended period of time. Evidence from SEM imaging suggests that while loss of surface area is still apparent after many cycles, the porous structure is retained. EDS line scans show that as ceria SPF-G structures are subjected to an increasing number of cycles, their oxidation becomes increasingly homogenous throughout the bulk material.

This work presents continuous thermochemical cycling of porous ceria to a degree not previously seen. While a downward trend in reactivity and loss of surface area is apparent after 2000 cycles, reactive stability is possible after some greater number of cycles. The significant retention of reactivity observed after 2000 cycles (>86\%) may correspond to several months of operation in an on-sun reactor system. These points demonstrate the potential of ceria SPF-G or similar porous structures in a commercial solar thermochemical reactor that must operate continuously over many cycles. 


\section{Acknowledgements}

The authors would like to thank W.G. Sawyer at the University of Florida for use of SEM and EDS imaging capacities. This work was supported in part by the US Department of Energy, ARPA-E: Award Number DE-AR0000184.

\section{References}

[1] T. Kodama, "High-temperature solar chemistry for converting solar heat to chemical fuels," Prog. Energy Combust., vol. 29, pp. 567-597, 2003.

[2] V. Hacker, R. Fankhauser, G. Faleschini, H. Fuchs, K. Friedrich, M. Muhr and K. Kordesch, "Hydrogen production by steam-iron process," J. Power Sources, vol. 86, pp. 531-535, 2000.

[3] R. Stehle, M. Bobek, R. Hooper and D. Hahn, "Oxidation reaction kinetics for the steam-rion process in support of hydrogen production," Int. J. Hydrogen Energy, vol. 36, pp. 15125-15135, 2011.

[4] A. Steinfeld, "Solar thermochemical production of hydrogen - a review.," Solar Energy, vol. 78, pp. 603-615, 2005.

[5] P. Furler, J. Scheffe and A. Steinfeld, "Syngas production by simultaneous splitting of $\mathrm{H}_{2} \mathrm{O}$ and $\mathrm{CO}_{2}$ via ceria redox reactions in a high-temperature solar reactor," Energy Environ. Sci., vol. 5, pp. 60986103, 2012.

[6] A. Stamatiou, P. Loutzenhiser and A. Steinfeld, "Solar Syngas Production via $\mathrm{H}_{2} \mathrm{O} / \mathrm{CO}_{2}-\mathrm{Splitting}$ Thermochemical Cycles with $\mathrm{Zn} / \mathrm{ZnO}$ and $\mathrm{FeO} / \mathrm{Fe}_{3} \mathrm{O}_{4}$ Redox Reactions," Chem. Mater., vol. 22, pp. 851-859, 2010.

[7] P. Loutzenhiser and A. Steinfeld, "Solar syngas production from $\mathrm{CO}_{2}$ and $\mathrm{H}_{2} \mathrm{O}$ in a two-step thermochemical cycle via $\mathrm{Zn} / \mathrm{ZnO}$ redox reactions: Thermodynamic cycle analysis," Int. J. Hydrogen Energy, vol. 36, pp. 12141-12147, 2011.

[8] S. Abanades and I. Villafan-Vidales, " $\mathrm{CO} 2$ valorisation based on $\mathrm{Fe}_{3} \mathrm{O}_{4} / \mathrm{FeO}$ thermochemical redox reactions using concentrated solar energy," Int. J. Energy Res., vol. 37, pp. 598-608, 2013.

[9] L. Xiao, S.-Y. Wu and Y. Li, "Advances in solar hydrogen production via two-step water-splitting thermochemical cycles based on metal redox reactions," Renewable Energy, vol. 41, pp. 1-12, 2012.

[10] T. Nakamura, "Hydrogen-production from water utilizing solar heat at high-temperatures," Solar Energy, vol. 19, pp. 467-475, 1976.

[11] A. Steinfeld, S. Sanders and R. Palumbo, "Design aspects of solar thermochemical engineering - A case study: Two-step water-splitting cycle using the $\mathrm{Fe}_{3} \mathrm{O}_{4} / \mathrm{FeO}$ redox system," Solar Energy, vol. 65, 
pp. 43-53, 1998.

[12] P. Charvin, S. Abanades, G. Flamant and F. Lemort, "Two-step water splitting thermochemical cycle based on iron oxide redox pair for solar hydrogen production," Energy, vol. 32, pp. 1124-1133, 2007.

[13] M. Bobek, R. Stehle and D. Hahn, "Investigation of Iron Oxide Morphology in a Cyclic Redox Water Splitting Process for Hydrogen Generation," Materials, vol. 5, pp. 2003-2014, 2012.

[14] Y. Tamaura, A. Steinfeld, P. Kuhn and K. Ehrensberger, "Production of solar hydrogen by a novel, 2step water-splitting thermochemical cycle," Energy, vol. 20, pp. 325-330, 1995.

[15] H. Kaneko, N. Kojima, N. Hasegawa, M. Inoue, R. Uehara, N. Gokon, Y. Tamaura and S. Taizo, "Reaction mechanism of $\mathrm{H}_{2}$ generation for $\mathrm{H}_{2} \mathrm{O} / \mathrm{Zn} / \mathrm{Fe}_{3} \mathrm{O}_{4}$ system," Int. J. Hydrogen Energy, vol. 27, pp. 1023-1028, 2002.

[16] T. Kodama, Y. Nakamuro and T. Mizuno, "Two-Step Thermochemical Water Splitting by Iron-Oxide on Stabilized Zirconia," J. Sol. Energy-T ASME, vol. 128, pp. 3-7, 2006.

[17] M. Roeb, N. Gathmann, M. Neises, C. Sattler and R. Pitz-Paal, "Thermodynamic analysis of two-step solar water splitting with mixed iron oxides," Int. J. Energy Res., vol. 33, pp. 893-902, 2009.

[18] L. Song, H. Kang and S. Park, "Thermally stable iron based redox catalysts for the thermo-chemical hydrogen generation from water," Energy, vol. 42, pp. 313-320, 2012.

[19] A. Steinfeld, "Solar hydrogen production via a two-step water-splitting thermochemical cycle based on Zn/ZnO redox reactions," Int. J. Hydrogen Energy, vol. 27, pp. 611-619, 2002.

[20] A. Weidenkaff, A. Reller, A. Wokaun and A. Steinfeld, "Thermogravimetric analysis of the $\mathrm{ZnO} / \mathrm{Zn}$ water splitting cycle," Thermochimica Acta, vol. 359, pp. 69-75, 2000.

[21] B. Bulfin, A. Lowe, K. Keogh, B. Murphy, O. Lubben, S. Krasnikov and I. Shvets, "Analytical Model of $\mathrm{CeO}_{2}$ Oxidation and Reduction," J. Phys. Chem. C, vol. 117, pp. 24129-24137, 2013.

[22] L. Venstrom, N. Petkovich, S. Rudisill, A. Stein and J. Davidson, "The effects of morphology on the oxidation of ceria by water and carbon dioxide," J. Sol. Energy Eng., vol. 134, pp. 1-8, 2010.

[23] H. Kaneko and Y. Tamaura, "Reactivity and XAFS study on (1-x) $\mathrm{FeO}_{2}-\mathrm{xNiO}(\mathrm{x}=0.025-0.3)$ system in the two-step water-splitting reaction for solar H2 production," J. Phys. Chem. Solids, vol. 70, pp. 1008-1014, 2009.

[24] Q.-L. Meng, C. Lee, H. Kaneko and Y. Tamaura, "Solar thermochemical process for hydrogen production via two-step water splitting cycle based on $\mathrm{Ce}_{1-x} \mathrm{Pr}_{x} \mathrm{O}_{2-\delta}$ redox reaction," Thermochimica Acta, vol. 532, pp. 134-138, 2012.

[25] S. Abanades, A. Le Gal, A. Cordier, G. Peraudeau, G. Flamant and A. Julbe, "Investigation of reactive cerium-based oxides for $\mathrm{H} 2$ production by thermochemical two-step water-splitting," J. Mater. Sci., 
vol. 45, pp. 4163-4173, 2010.

[26] A. Le Gal, S. Abanades and G. Flamant, " $\mathrm{CO}_{2}$ and $\mathrm{H}_{2} \mathrm{O}$ Splitting for Thermochemical Production of Solar Fuels Using Nonstoichiometric Ceria and Ceria/Zirconia Solid Solutions," Energy \& Fuels, vol. 25, pp. 4836-4845, 2011.

[27] P. Furler, J. Scheffe, M. Gorbar, L. Moes, U. Vogt and A. Steinfeld, "Solar Thermochemical $\mathrm{CO}_{2}$ Splitting Utilizing A Reticulated Porous Ceria Redox System," Energy \& Fuels, vol. 26, pp. 7051-7059, 2012.

[28] W. Chueh, C. Falter, M. Abbot, D. Scipio, P. Furler, S. Haile and A. Steinfeld, "High-Flux Solar-Driven Thermochemical Dissociation of $\mathrm{CO}_{2}$ and $\mathrm{H}_{2} \mathrm{O}$ Using Nonstoichiometric Ceria," Science, vol. 330, pp. 1797-1801, 2010.

[29] J. Miller, M. Allendorf, R. Diver, L. Evans, N. Siegle and J. Stuecker, "Metal oxide composites and structures for ultra-high temperature solar thermochemical cycles," J. Mater. Sci., vol. 43, pp. 4714$4728,2008$.

[30] J. Lapp, J. Davidson and W. Lipinski, "Efficiency of two-step solar thermochemical nonstoichiometric redox cycles with heat recovery," Energy, vol. 37, pp. 591-600, 2012.

[31] W. Chueh and S. Haile, "A thermochemical study of ceria: exploiting an old amterial for new modes of energy conversion and $\mathrm{CO}_{2}$ migration," Phil. Trans. R. Soc. A, vol. 368, pp. 3269-3294, 2010.

[32] K. Allen, E. Coker, N. AuYeung and J. Klausner, "Cobalt Ferrite in YSZ for Use as Reactive Material in Solar Thermochemical Water and Carbon Dioxide Splitting, Part I: Material Characterization," JOM, vol. 65, pp. 1670-1681, 2013.

[33] I. Ermanoski, J. Miller and M. Allendorf, "Efficiency maximization in solar-thermochemical fuel production: challenging the concept of isothermal water splitting," Phys. Chem. Chem. Phys., vol. 16, pp. 8418-8427, 2014. 